DOE/NASA/0330-2

NASA CR-180803

\title{
Wind Tunnel Evaluation of a Truncated NACA 64-621 Airfoil for Wind Turbine Applications
}

S.P. Law and G.M. Gregorek

Ohio State University

Columbus, Ohio 43210

July 1987

Prepared for

National Aeronautics and Space Administration

Lewis Research Center

Cleveland, Ohio 44135

Under Grant NAG 3-330

for

U.S. DEPARTMENT OF ENERGY

Conservation and Renewable Energy

Wind/Ocean Technology Division

Washington, D.C. 20545

Under Interagency Agreement DE-Al01-76ET20320 
WINI TUNNEL EVALUATION

OF A TRUNCATED NACA 64-621 AIRFOIL

FOR WIND TURBINE APPLICATIONS

by S.P. Law and G.M. Gregorek

\begin{abstract}
$\underline{\text { ABSTRACT }}$
An experimental program to measure the aerodynamic performance of a NACA 64-621 airfoil with a truncated trailing edge for wind turbine applications has been conducted in The Ohio State University Aeronautical and Astronautical Research Laboratory 6 in. $x 22$ in. pressurized wind tunnel. The blunted or trailing edge truncated (TET) airfoil has an advantage over similar sharp trailing edge airfoils because it is able to streamline a larger spar structure, while also providing aerodynamic properties that are quite good. Surface pressures were measured and integrated to determine the lift, pressure drag, and moment coefficients over angles of attack ranging from $-14^{\circ}$ to $+90^{\circ}$ at Mach 0.2 and Reynolds numbers of $1,000,000$ and 600,000 . Results are compared to the NACA 0025, 0030, and 0035 thick airfoils with sharp trailing edges. Comparison shows that the 30 percent thick NACA 64-621-TET airfoil has higher maximum lift, higher lift curve slope, lower drag at higher lift coefficients, and higher chordwise force coefficient than similar thick airfoils with sharp trailing edges.
\end{abstract}

INTRODUCTION

Wind turbines, proposed as an alternate energy source for the last decade, have received considerable attention. As wind turbines have increased in size, some proposed designs have rotors 400 feet in diameter, capable of producing over 7 megawatts of electric power. The need for thick airfoils that can envelop the deep spars often required near the rotor hub for 
structural integrity has become apparent. Available data on thick airfoils is limited, especially at the Reynolds numbers and angles of attack experienced by large wind turbines.

This report presents experimental data on the aerodynamic performance of a new airfoil for wind turbine applications. The airfoil is unusual in that it has a very blunt trailing edge instead of the conventional sharp trailing edge. Besides being able to streamline a larger internal structure, the blunted thick airfoil can have aerodynamic advantages over existing airfoils. Reference 1, for example, indicates that blunting the trailing edge of a 40 percent thick airfoil increases maximum lift-to-drag ratio by 100 percent. The effect of blunting the trailing edge of thick airfoils is to reduce the sharp curvature near the trailing edge, thus reducing the adverse pressure gradient caused by pressure recovery at the trailing edge. Thick boundary layers associated with low Reynolds numbers, which can occur on the inboard sections of wind turbine blades, are most susceptible to flow separation due to a strong adverse pressure gradient. Any reduction in the magnitude of an adverse pressure gradient will reduce flow separation, and can result in better aerodynamic performance.

Since available computer codes fail at modeling unsteady flow behind blunt base airfoils, wind tunnel testing is necessary. A 30 percent thick airfoil, with the trailing edge truncated (TET), was tested in The Ohio State University Aeronautical and Astronautical Research Laboratory (OSU AARL) 6 in. $x 22$ in. two-dimensional wind tunnel. As shown in figure 1, the trailing edge flap section of previously-tested standard NACA 64-621 model was removed, providing a 30 percent thick airfoil (compared to the shortened chord) with a blunt base, referred to as the NACA 64-621-TET. The resulting thickness of the trailing edge was 53 percent of the maximum thickness of ine airfoil. Dimensionless coordinates for this airfoil section are listed in Table 1.

To characterize the conditions experienced by wind turbine root sections, the NACA 64-621-TET was tested at Reynolds numbers of 600,000 and $1,000,000$ 
from $-14^{\circ}$ to $+90^{\circ}$ angle of attack. Surface pressures were integrated to determine the lift, pressure drag, and moment forces. The wake survey method of measuring drag could not be used because of inaccurate results caused by highly unsteady flow behind the blunt trailing edge.

NACA data for 25, 30, and 35 percent thick symmetrical airfoils (NACA 0025, 0030, and 0035, respectively) with sharp trailing edges was available (refs. 2 and 3 ), and is compared to the NACA 64-621-TET. This comparison evaluates aerodynamic effects of truncating the trailing edge of a thick airfoil. Airfoils contours for the NACA 0025, NACA 0030, NACA 0035 are also shown in figure 1 .

\title{
EXPERIMENTAL FACILITIES
}

\author{
Description of Facilities
}

Testing was performed in the OSU AARL 6 in. $x 22$ in. pressurized blow-down wind tunnel. A schematic of the tunnel is shown in figure 2. The tunnel has a Mach number range from 0.2 to 1.1 , and a maximum stagnation pressure of 65 psia. At Mach 0.2 the tunnel is capable of simulating full-scale flight conditions at Reynolds (Re) numbers of 2,000,000 to 7,000,000 per foot. The tunnel is interfaced with a Harris/6 computer providing near on-line data acquisition and reduction.

The NACA 64-621-TET model was molded of an aluminum-epoxy composite material. The configuration of the model is shown in figure 3 . The model contains 38 surface pressure taps, each 0.02 in. orfice diameter, connected by $0.06 \mathrm{in}$. 0.D. imbedded plastic tubes that lead through the mounting blocks and brass tubes to the pressure scanning equipment. The mounting blocks at the ends of the model were inserted into rectangular cut-outs of two circular plates. The circular plates are mounted into the test section, and can be rotated to any desired angle of attack. Two configurations of the model were tested: One with a leading edge trip strip 
(tripped), and the other without (smooth). The trip stri? was a piece of double-sided tape applied to the upper and lower surfaces for a distance of 5 percent of the chord on either side of leading edge.

\section{Testing Procedure}

A typical test run lasts 15 to 20 seconds during which the surface pressures are measured for a single Mach number, Reynolds number, and angle of attack. Upon opening the air-valve (fig. 2), the Harris/6 computer controls the test sequence. Each surface pressure is locked into a multi-ported valve, and a pitot probe, located one chord length downstream of the model, is commanded to traverse the airfoil wake. After the pitot probe has crossed the wake, the Harris/6 closes the air-valve and begins data reduction. The trapped surface pressures are measured and displayed on the operator's CRT in a pressure distribution versus chord location format. The distribution is integrated to determine the lift, pressure drag, and moment coefficients. The raw data is stored on magnetic tape. Within two minutes hard copies of the results are printed out, and the tunnel prepared for another test run.

Because of the blunt base, the usual wake survey method was not used for arag measurement. The wake survey is an accurate way to determine total orag of a conventional airfoil, but it is dependent upon an accurate integration of the wake behind the model. Figure 4 shows wake surveys for a standard NACA 64-621 airfoil and the NACA 64-621-TET at $0^{\circ}$ angle of attack. Unlike the standard NACA 64-621, the NACA 64-621-TET wake plot shows highly erratic flow behind the model. The unsteady wake induces flow angles onto the pitot probe resulting in drag values that are too low. Fortunately, the pressure drag is more representative of the large drag values present in highly unsteady flow. Pressure drag, therefore, was used throughout the NACA 64-621-TET wind tunnel test (ref. 4). 
RESULTS AND DISCUSSION OF WIND TUNNEL TESTING

Lift

Lift coefficient versus angle of attack for the NACA 64-621-TET is presented in figure 5. Tripped configurations have maximum lift coefficients of 1.29 at $\operatorname{Re}=1,000,000$ and 1.28 at $\operatorname{Re}=600,000$. The smooth NACA 64-621-TET has a maximum lift coefficient of 1.25 at $\operatorname{Re}=600,000$ and 1.13 it $\operatorname{Re}=1,000,000$. Both smooth NACA 64-621-TET Reynolds number cases were tested to a high enough angle of attack to show their favorable trailing edge stall, i.e. flow separation traveling from the trailing edge towards the leading edge. A11 NACA 64-621-TET run condition cases have the relatively large negative maximum lift coefficients of about -1.2. Also shown in figure 5 is the lift coefficient approaching zero as the angle of attack approaches zero. This is a result of decreased camber of the standard NACA 64-621 when the aft 30 percent was removed to make the NACA 64-621 TET. This shows that the NACA 64-621-TET is essentially a symmetric section.

The high lift curve slopes of the standard NACA 64-621-TET are apparent in figure 5. The lift curve slopes per degree are 0.108 and 0.103 at $\mathrm{Re}=$ $1,000,000$, and 0.110 and 0.109 at $R e=600,000$, for smooth and tripped configurations respectively. These lift curve slopes for a 30 percent thick airfoil with a blunt base are quite remarkable when compared to the 0.11 per degree lift curve slope from thin airfoil theory.

Drag

Because of the blunt base, the drag values for the NACA 64-621-TET are much higher than the drag values for sharp trailing edge airfoils at low angles of attack. The high drag at low angles of attack is due to base drag, which is the result of low aerodynamic presure on the blunt trailing edge. Figure 6 shows the base drag and pressure drag for the tripped $R e=1,000,000$ case. At low angles of attack, base drag is 60 percent of the measured pressure 
drag. Base dray was calculated by multiplying the average value of the pressure coefficient at the blunt base times the blunt base thickness. All values were corrected for the angle of attack. As the angle of attack is increased, the base drag becomes less of an influence on total pressure drag.

Drag coefficients for different test conditions versus the angle of attack are shown in figure 7 . The plot shows typical results with the drag increasing sharply after angles of attack exceed $+6^{\circ}$. From the stall angles determined from figure 5, drag values at stall are 0.0850 for tripped at $\operatorname{Re}=$ $1,000,000 ; 0.0900$ for tripped and smooth at $\operatorname{Re}=600,000$; and 0.0950 for smooth at $\operatorname{Re}=1,000,000$ conditions.

Lift coefficients versus the drag coefficients are plotted in figure 8 . The drag polar is generally asymmetric, with slightly better lift-to-drag ratios at positive lift coefficients. Maximum lift-to-drag ratios are 20 for tripped at $\operatorname{Re}=600,000 ; 18$ for tripped at $\operatorname{Re}=1,000,000$, and about 13 for smooth at both Reynolds numbers. The smooth $R e=1,000,000$ has the lowest $C_{D O}$ (drag coefficient at $0^{\circ}$ angle of attack) of 0.0450 , because of its thin boundary layer resulting from laminar flow and higher Reynolds number. Other $C_{D 0}$ values are 0.0690 for smooth at $R e=600,000 ; 0.0570$ for tripped at $\operatorname{Re}=1,000,000$; and 0.0500 for tripped at $\operatorname{Re}=600,000$ conditions. For comparison, sharp trailing edge airfoils generally have $C_{D O}$ values near 0.01 for comparable thicknesses.

High Angles of Attack

To study "off design" conditions that wind turbine airfoils experience, such as during rotor start-up or hurricane winds, the lift and drag coefficients up to a $90^{\circ}$ angle of attack were measured and are shown in figure 9. At a $45^{\circ}$ angle of attack, the lift and drag are very nearly equal, which produces a resultant force essentially normal to the chord line. As the angle of attack is increased further to $90^{\circ}$, the NACA 64-621-TET behaves more and 
more like a flat plate (ref. 5), as shown by the dashed lines in figure 9. The low Reynolds number drag coefficient reaches 2.0 at $80^{\circ}$, but dips down to 1.85 at a $90^{\circ}$ angle of attack. The fluctuation in data is caused by a combination of the highly unsteady flow and the "snapshot" method used to measure surface pressures and, hence, drag coefficients.

Moment

Figure 10 shows the moment coefficient versus angle of attack for the NACA 64-621-TET which is typical for all the test conditions. When compared to the zero moment coefficients of symmetric airfoils, the NACA 64-621-TET has relatively large negative pitching moment coefficients. These are most likely caused by the method used in the data reduction program for determining moment coefficients for the NACA 64-621-TET. The data reduction program assumed the aerodynamic center at the quarter chord. With increasing angle of attack, the erratic boundary layer development for a truncated airfoil may cause a shift in the aerodynamic center, which would result in slightly erroneous NACA 64-621-TET moment coefficients. The moment coefficient becomes positive at angles of attack near stall due to thinning of the boundary layer near the trailing edge lower surface (creating a lower pressure) and the thickening of the boundary layer near the trailing edge upper surface (creating a higher pressure, ref. 4 ). The iet result is a positive pitching moment coefficient.

\section{Chordwise Force}

The chordwise force coefficient is a resolution of the lift and drag forces along the chordline of the airfoil. Chordwise force coefficient is a coefficient that is usually only applied to wind turbine airfoils. Because the chord line is approximately parallel to the plane of rotation, the chordwise force coefficient determines the torque generated from an airfoil's lift and drag forces. It is therefore a very important 
coefficient in choosing an airfoil for a wind turbine. The chordwise force is referenced positive in the direction of rotary motion and is calculated using the following equation:

$$
C_{C}=C_{L} \sin (\alpha)-C_{D} \cos (\alpha)
$$

where $C_{L}$ is the lift coefficient, $C_{D}$ is the drag coefficient, and $\alpha$ is the angle of attack. A positive chordwise coefficient indicates a power-producing force, and a negative coefficient indicates a braking-force.

Figure 11 presents chordwise coefficient versus angle of attack for the NACA 64-621-TET. Only the smooth configurations were tested to a high enough angle of attack to determine the maximum chordwise force coefficient. Tripped configurations closely follow the smooth $\operatorname{Re}=600,000$ case, and appear as though they would reach the same maximum value. Both smooth Reynolds number cases obtain a maximum chordwise coefficient at a $20^{\circ}$ angle of attack with 0.279 at $\operatorname{Re}=600,000$, and 0.293 at $\operatorname{Re}=1,000,000$. From figure 11, the best design angle of attack for the NACA 64-621-TET is about $20^{\circ}$, which is the angle of attack that will produce the most torque from the lift and drag forces. After chordwise "stall" at about 25 degrees, performance of the NACA 64-621-TET degrades considerably with increasing angle of attack.

Figure 12 presents the chordwise coefficient up to $90^{\circ}$ angle of attack. Recall that this angle of attack range was investigated for off-design cases, where torque-producing forces are not desired. The figure shows that the NACA 64-621-TET has negative thrust (braking) characteristics after $35^{\circ}$ angle of attack. This negative torque is desirable to prevent the wind turbine rotor from overspeeding as the angle of attack increases in very high winds. However, start-up of the turbine would also be more difficult. 
COMPARISON AGAINST THICK AIRFOILS WITH SHARP TRAILING EDGES

The purpose of this comparison is to recognize the aerodynamic effects of blunting the trailing edge of a 30 percent thick airfoil. A comparison is made between the OSU NACA 64-621-TET data and the NACA data for the 0025, 0030, and 0035 airfoils. These airfoils, which are in the NACA 4-Series, were chosen for comparison because the data was readily available, and the NACA 64-621-TET at small angles of attack had lift characteristics similar to a symmetric airfoil. The NACA 0025 and 0035 were tested in the NACA Full Scale Wind Tunnel (ref. 2), and the NACA 0030 tested in the NACA Variable Density Wind Tunnel (ref. 3). Because the NACA 4-Series airfoils were intended for aircraft applications, models were tested at $\operatorname{Re}=3,200,000$.

Although the NACA 4-Series data was tested at higher Reynolds numbers, an effective comparison can still be made as long as the performance improvement of the higher Reynolds Number is kept in mind. Higher Reynolds Numbers reduce the boundary layer thickness resulting in reduced pressure drag. For example, a laminar boundary layer for this model is 76 percent thinner at $\operatorname{Re}=3,200,000$ than at $\operatorname{Re}=1,000,000$. A turbulent boundary layer is 26 percent thinner at $\operatorname{Re}=3,200,000$ than at $\operatorname{Re}=1,000,000$ (ref . 6). Higher Reynolds numbers also move the transition point towards the leading edge so that more of the airfoil is under the influence of an energized turbulent boundary layer. Turbulent boundary layer delays flow separation to a higher angle of attack resulting in a higher maximum lift coefficient.

Lift

A comparison of lift coefficient versus angle of attack for the NACA 64-621-TET and the sharp trailing edge NACA 4-Series is shown in figure 13. The NACA 64-621-TET has a much higher maximum lift coefficient and lift curve slope. The maximum lift coefficient for the tripped NACA 64-621-TET at a Reynolds number of $1,000,000$ is 1.29 . This maximum lift coefficient is 
60 percent higher than the NACA 0035, 20 percent higher than the NACA 0030, and 17 percent higher than the NACA 0025 maximum lift coefficients. The non-linear lift curve slope at low angles of attack for the NACA 0035 can be attributed to the non-linear boundary layer build up on the upper surface thereby changing the effective airfoil profile (ref. 7).

A comparison of lift curve slopes is shown in figure 14. The lift curve slope of the NACA 4-Series degrades considerably with increasing thickness, while the NACA 64-621-TET has a lift curve slope that is much closer to the "theory" lift curve slope. The theoretical lift curve slope shown in figure 14 involves an empirical correction to the thin airfoil theory lift curve slope of 0.11 per degree. The second term in the equation accounts for increased lift curve slope expected theoretically when increasing the thickness of an airfoil (ref. 8). Figures 13 and 14 show that the NACA 64-621-TET has a considerable increase in maximum lift and lift curve slope over all of the NACA 4-Series airfoils with sharp trailing edges.

\section{Drag}

Figure 15 compares drag coefficients versus angle of attack for the NACA 64-621-TET and NACA 4-Series airfoils. At stall angles of about $18^{\circ}$ angle of attack, the NACA 0030 and NACA 0035 have essentially the same drag of the NACA 64-621-TET. Although the NACA 0030 and 0035 have lower drag at low angles of attack, the NACA 64-621-TET, NACA 0030, and NACA 0035 have equivalent drag at high angles of attack.

A discrepancy in the NACA 0030 drag values is noticed with the thinner NACA 0030 airfoil having a larger minimum drag coefficient than the thicker NACA 0035 airfoil. This discrepancy in NACA $0030 \mathrm{drag}$ values can be attributed to a well-known turbulence problem of the Variable Density Wind Tunnel in which the this airfoil was tested. The lower drag values for all the NACA 4-Series airfoils can be explained in part by effects of the higher Reynolds number $(3,200,000)$ at which the NACA 4-Series were tested. 
Lift coefficients versus drag coefficients are shown in figure 15 for the NACA 64-621-TET, NACA 0025, NACA 0030, and NACA 0035 airfoils. The maximum lift-to-drag ratios of the NACA 4-Series airfoils are better than the NACA 64-621-TET with the lowest ratio of 21 for the NACA 0030 being slightly above the largest ratio of 20 for the tripped NACA 64-621-TET at $\mathrm{Re}=$ 1,000,000. The NACA 64-621-TET, however, shows higher lift-to-drag ratios than the NACA 0030 and 0035 airfoils at lift coefficients above 0.8 .

Moment

Figure 17 compares the moment coefficients for the NACA 64-621-TET and NACA 4-Series airfoils. The NACA 0025 and NACA 0030 show typical symmetric characteristics of zero moment about the aerodynamic center throughout the angle of attack range. The NACA 0035, however, has a positive pitching moment coefficient at positive angles of attack. As mentioned earlier when discussing the positive pitching moments of the NACA 64-621-TET, boundary layer thickening on the upper surface forms a high pressure area and boundary layer thinning on the lower surface forms a low pressure area, which results in positive pitching moments for the NACA 0035.

\section{Chordwise Force}

A comparison of chordwise force coefficients for the NACA 64-621-TET and NACA 4-Series airfoils is shown in figure 18. The NACA 0020 and NACA 0035 maximum chordwise force values of 0.21 and 0.17 , respectively, are considerably lower than the tripped NACA 64-621-TET maximum chordwise force coefficient of 0.26 at $\operatorname{Re}=1,000,000$. The NACA 0025 has chordwise performance that is slightly better the NACA 64-621-TET. This plot shows that the NACA 64-621-TET wi11 produce more torque than the NACA 0030 and NACA 0035 at angles of attack above $8^{\circ}$.

A chordwise force coefficient comparison against a standard NACA 64-621 is made in figure 19. The standard NACA 64-621, which is a 21 percent thick 
airfoil with a sharp trailing edge as shown in figure 1, was tested earlier at the same conditions as the NACA 64-621-TET. This comparison was made to observe the effects of sharp and blunt trailing edges on chordwise coefficients at high angles of attack. Recall that these high angles of attack occur at high wind speeds when excess power may be produced. This comparative plot shows that the NACA 64-621-TET has negative chordwise forces, while the standard NACA 64-621 exhibits positive chordwise forces at high angles of attack.

\section{SUMMARY AND CONCLUSIONS}

An NACA 64-621 airfoil was modified into a 30 percent thick airfoil with a truncated trailing edge, referred to as the NACA 64-621-TET. Because of the blunted trailing edge, the NACA 64-621-TET can streamline a larger spar structure than the NACA 64-621 with a sharp trailing edge and the same chord dimension. Therefore it is a good candidate for root sections on wind turbine rotor blades. The purpose of this test was to investigate the aerodynamic performance of a 30 percent thick airfoil with a blunt base under the low Reynolds number and wide angle of attack range experienced by blade root sections of wind turbines.

The NACA 64-621-TET was wind tunnel tested in the OSU AARL 6 in. $x 22$ in. wind tunnel. The model was tested at Mach 0.2 and Reynolds numbers of $1,000,000$ and 600,000 based on the $2.8 \mathrm{in}$. chord of the model. To simulate conditions experienced by wind turbine blade root sections, the NACA 64-621-TET was tested at angles of attack ranging from $-14^{\circ}$ to $+90^{\circ}$. A comparison between the NACA 64-621-TET and other NACA thick airfoils with sharp trailing edges shows that the NACA 64-621-TET has higher maximum lift coefficient, higher lift curve slope, lower drag at higher lift coefficients, and higher maximum chordwise force coefficient than similar thick airfoils with sharp trailing edges.

This report has shown that blunting the trailing edge of a 30 percent thick airfoil results in increased aerodynamic performance over similar thick 
airfoils with sharp trailing edges. Based on this preliminary study, the NACA 64-621-TET airfoil is recommended as a candidate airfoil for the inboard sections of wind turbine blades.

\section{REFERENCES}

1. Hoerner, Sighard: Fluid-Dynamic Drag, Published by Author, 1965, pg. 3-22.

2. Bullivant, W. Kenneth: "Tests of the NACA 0025 and 0035 Airfoils in the Full-Scale Wind Tunnel," NACA Technical Report No. 708, 1941.

3. Jacobs, Eastman N., and Abbott, Ira H.: "Airfoil Section Data Obtained in the NACA Variable-Density Tunnel as Affected by Support Interference and Other Corrections," NACA Technical Report No. 669, 1939.

4. Gregorek, G. M.: "Design and Wind Tunnel Evaluation of a Symmetric Airfoil Series for Large Wind Turbine Applications," NASA CR-174764, May 1984.

5. Hoerner, Sighard F.: loc cit, p. 3-15.

6. Anderson, John D.: Introduction to Flight, McGraw-Hi11, New York, 1978.

7. Gregorek, G. M.: Private Communication, February, 1985.

8. Hoerner, Sighard F.: Fluid-Dynamic Lift, Published by Liselotte A. Hoerner, 1975. 
TABLE 1

NACA 64-621-TET Airfoil Coordinates (Trailing Edge Truncated)

\begin{tabular}{|c|c|c|c|}
\hline \multicolumn{2}{|c|}{$\begin{array}{c}\text { Upper } \\
\text { surface }\end{array}$} & \multicolumn{2}{|c|}{$\begin{array}{l}\text { Lower } \\
\text { surface }\end{array}$} \\
\hline$\overline{x / c, \%(a)}$ & $y / c, \%$ & $x / c, \%$ & $y / c, \%$ \\
\hline $\begin{array}{r}-0.121 \\
-0.054 \\
0.118 \\
0.827 \\
1.705 \\
10.032 \\
13.235 \\
21.849 \\
30.519 \\
34.868 \\
43.583 \\
56.673 \\
69.751 \\
82.769 \\
100.000\end{array}$ & $\begin{array}{r}1.094 \\
1.742 \\
2.415 \\
3.664 \\
4.696 \\
10.338 \\
11.787 \\
14.811 \\
16.956 \\
17.765 \\
18.905 \\
19.399 \\
18.284 \\
16.086 \\
12.027\end{array}$ & $\begin{array}{r}-0.121 \\
0.000 \\
0.654 \\
2.234 \\
4.409 \\
12.040 \\
15.246 \\
19.492 \\
27.933 \\
36.332 \\
44.706 \\
57.248 \\
69.802 \\
86.638 \\
99.362\end{array}$ & $\begin{array}{r}1.094 \\
0.000 \\
-1.359 \\
-2.857 \\
-4.060 \\
-6.632 \\
-7.366 \\
-8.175 \\
-9.366 \\
-10.118 \\
-10.486 \\
-10.247 \\
-8.862 \\
-6.078 \\
-3.720\end{array}$ \\
\hline \multicolumn{4}{|c|}{ Trailing edge section removed from standard NACA 64621 airfoi } \\
\hline $\begin{array}{l}100.000 \\
112.812 \\
125.530 \\
133.966 \\
142.401\end{array}$ & $\begin{array}{r}12.027 \\
8.464 \\
4.775 \\
2.371 \\
0.000\end{array}$ & $\begin{array}{r}99.362 \\
112.182 \\
125.097 \\
133.749 \\
142.401\end{array}$ & $\begin{array}{r}-3.720 \\
-1.477 \\
0.215 \\
0.715 \\
0.000\end{array}$ \\
\hline
\end{tabular}

(a) Coordinates given in percent of truncated chord dimension $c$ 

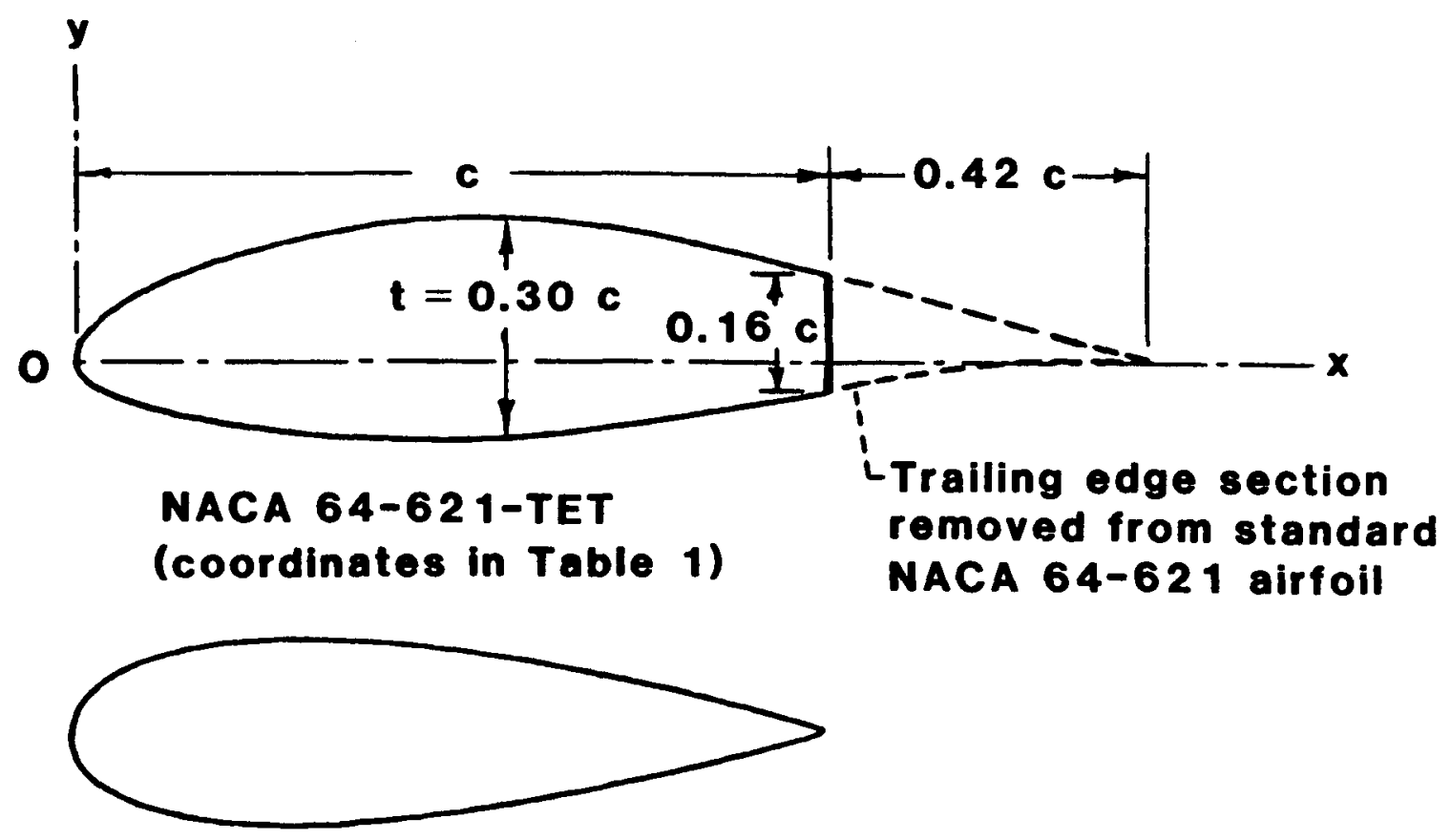

NACA 0025

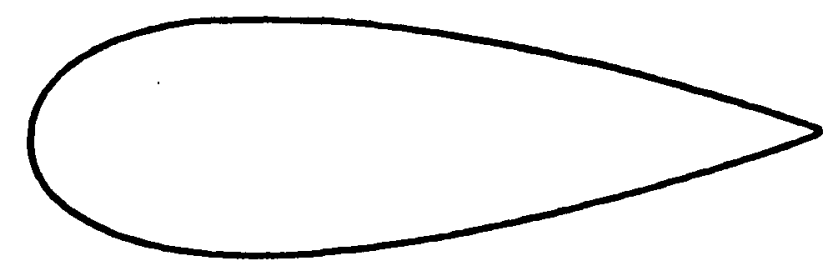

NACA 0030

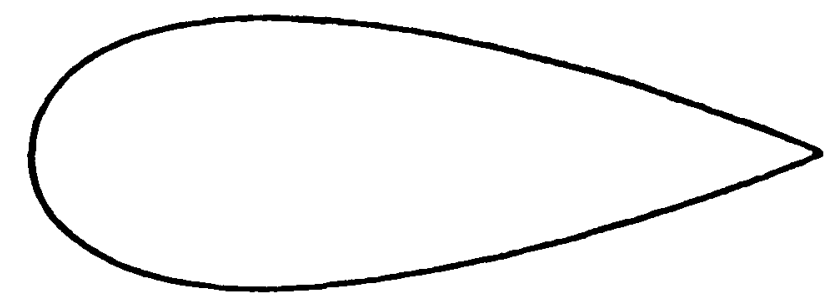

NACA 0035

Figure 1.- Section contour of the NACA 64-621-TET airfoil, compared to contours of airfoils in the NACA 4-Series. 


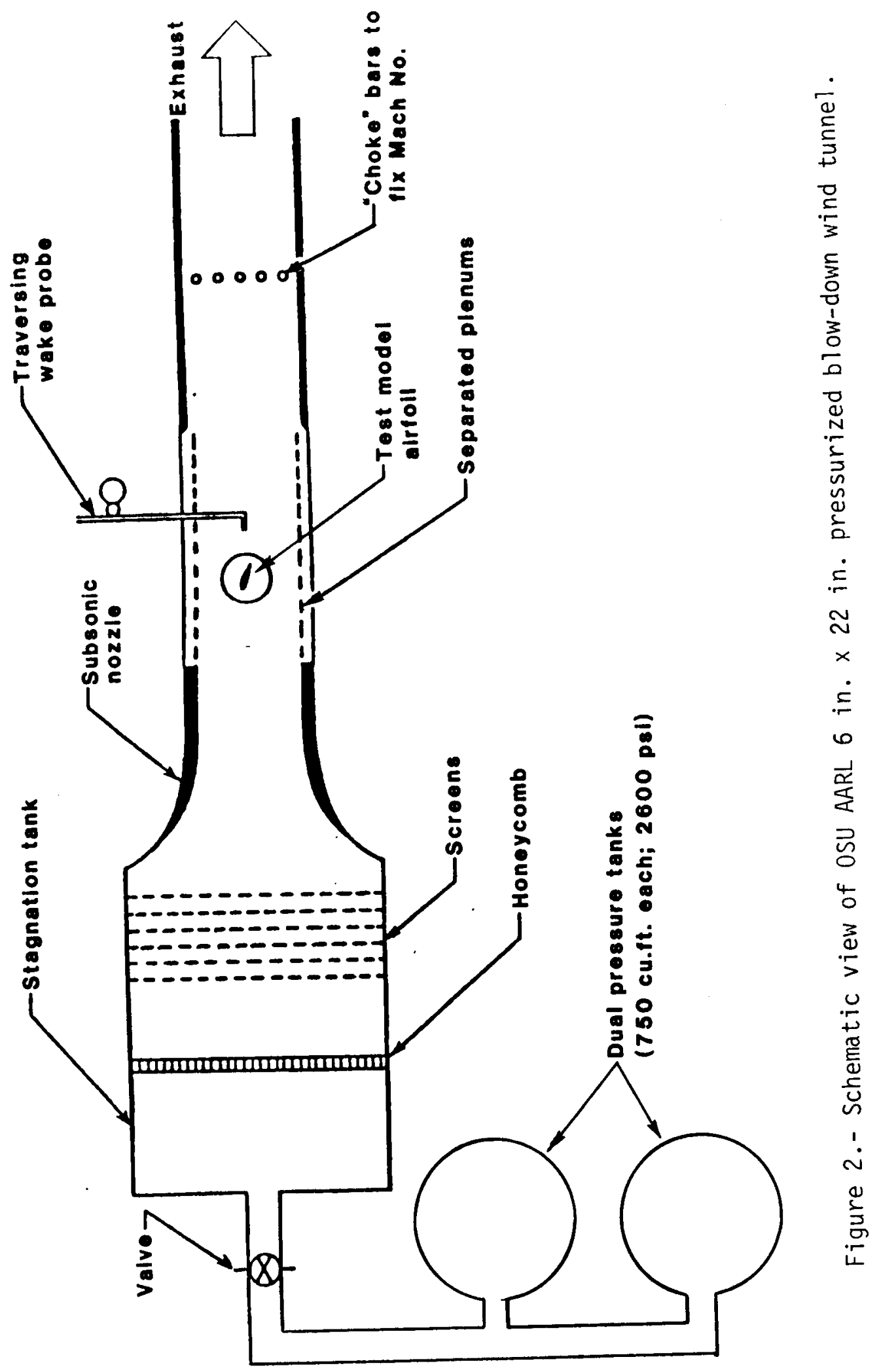




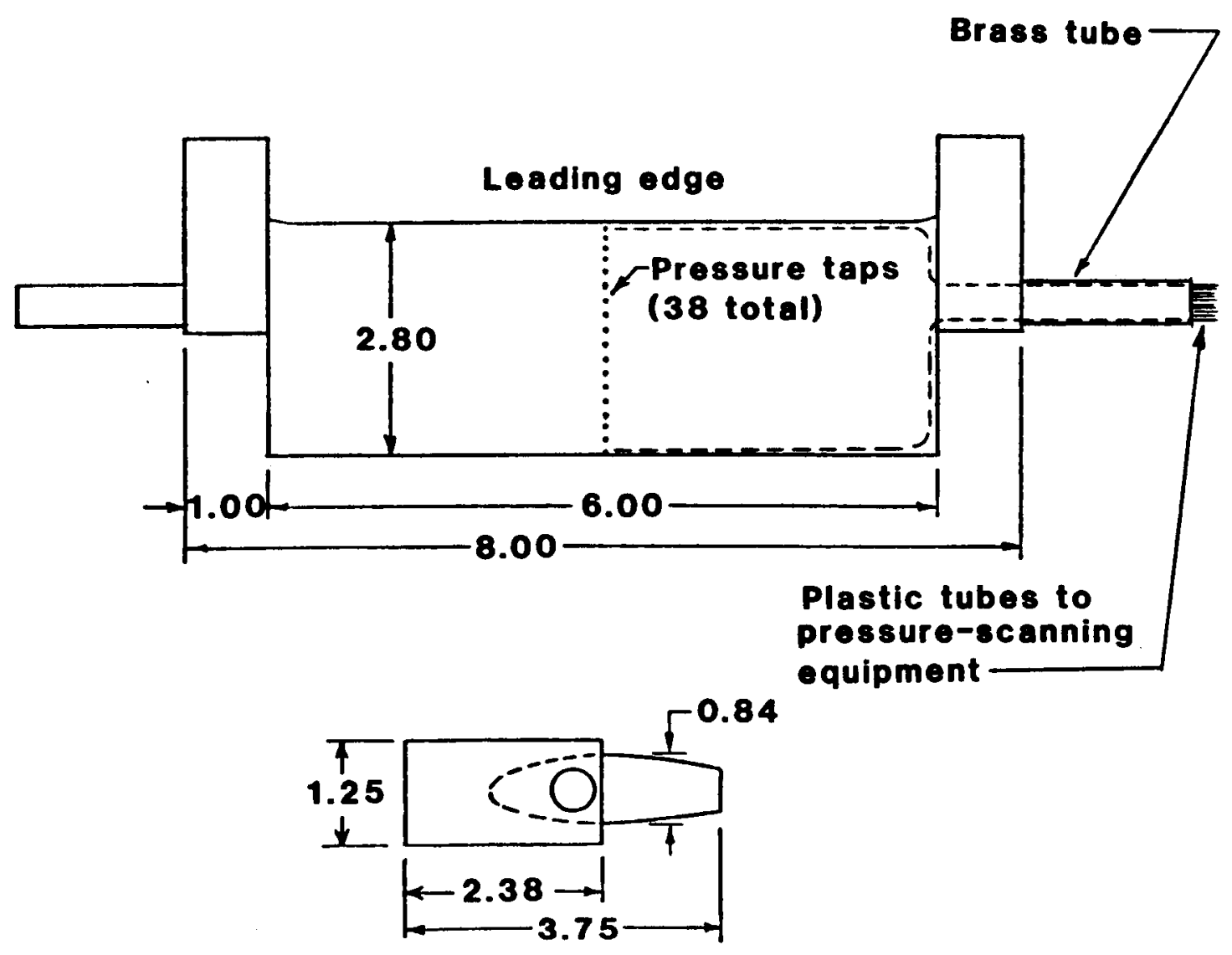

Figure 3.- Configuration of NACA 64-621-TET test model airfoi1 (al1 dimensions in inches). 


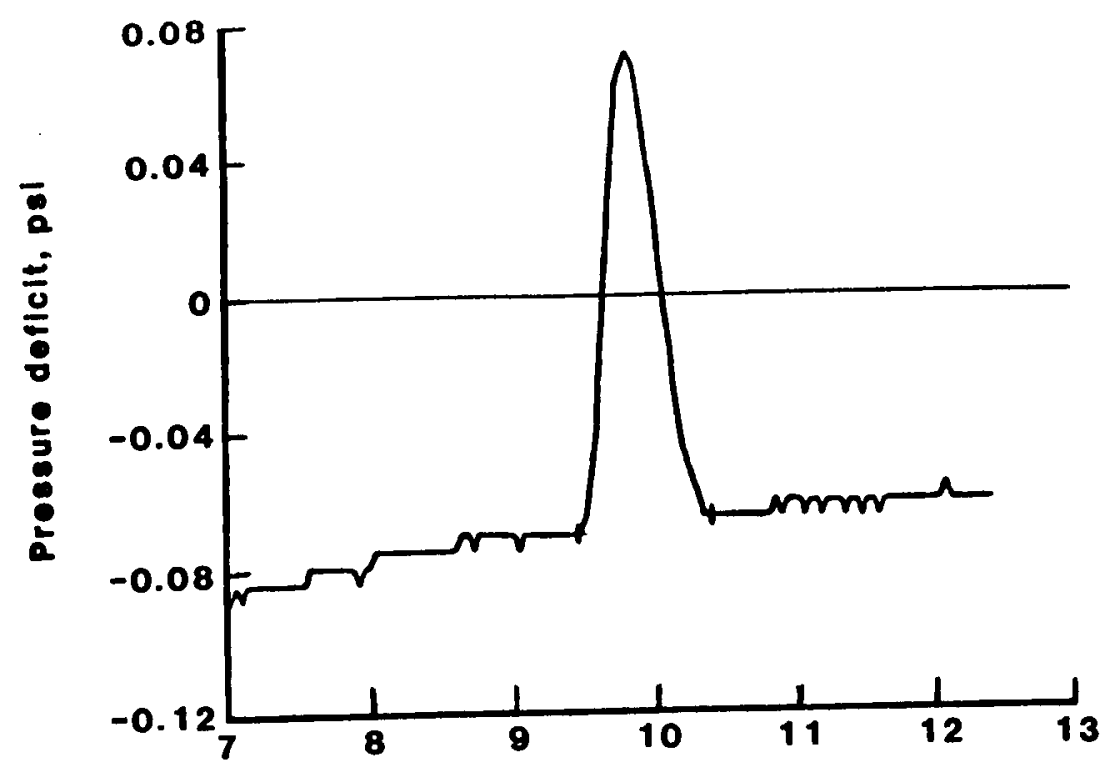

(a) Standard NACA 64-621 airfoil $(\alpha=0)$.

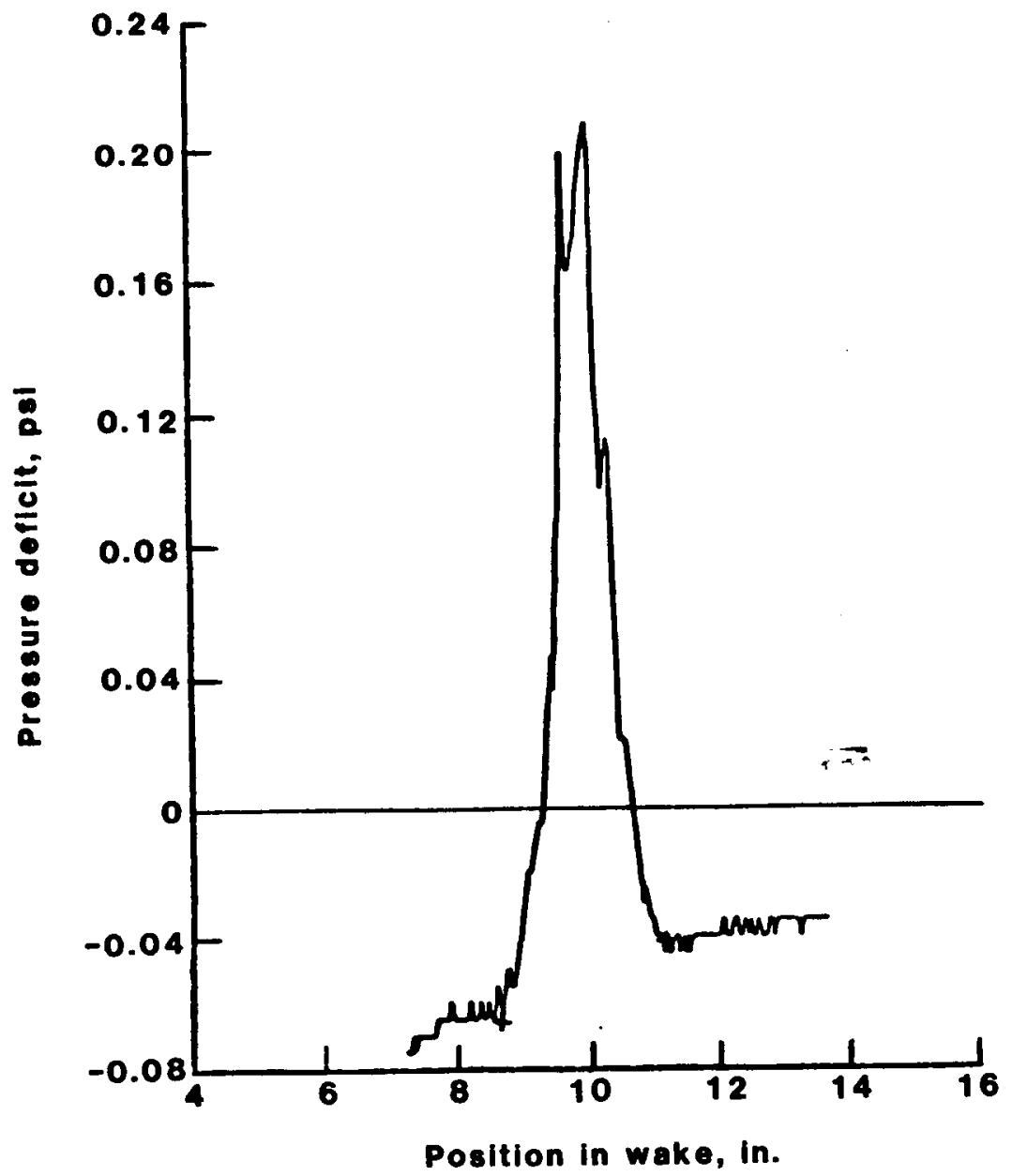

(b) NACA 64-621-TET airfoil $(\alpha=0)$.

Figure 4.- Wake pressure surveys of standard and truncated NACA 64-621 airfoils. 


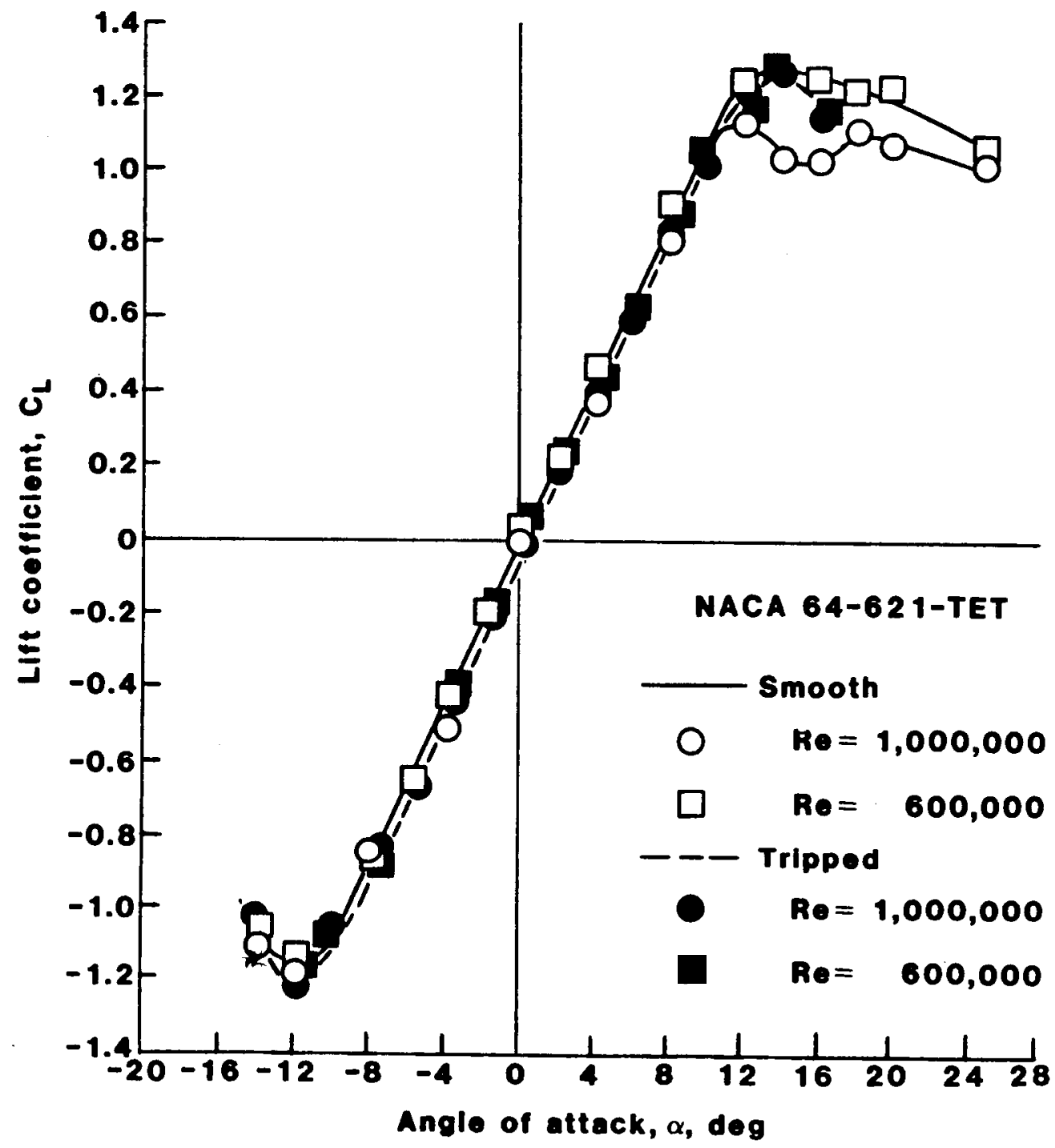

Figure 5.- Lift coefficient for the NACA 64-621-TET airfoil, in the smooth and tripped conditions. 


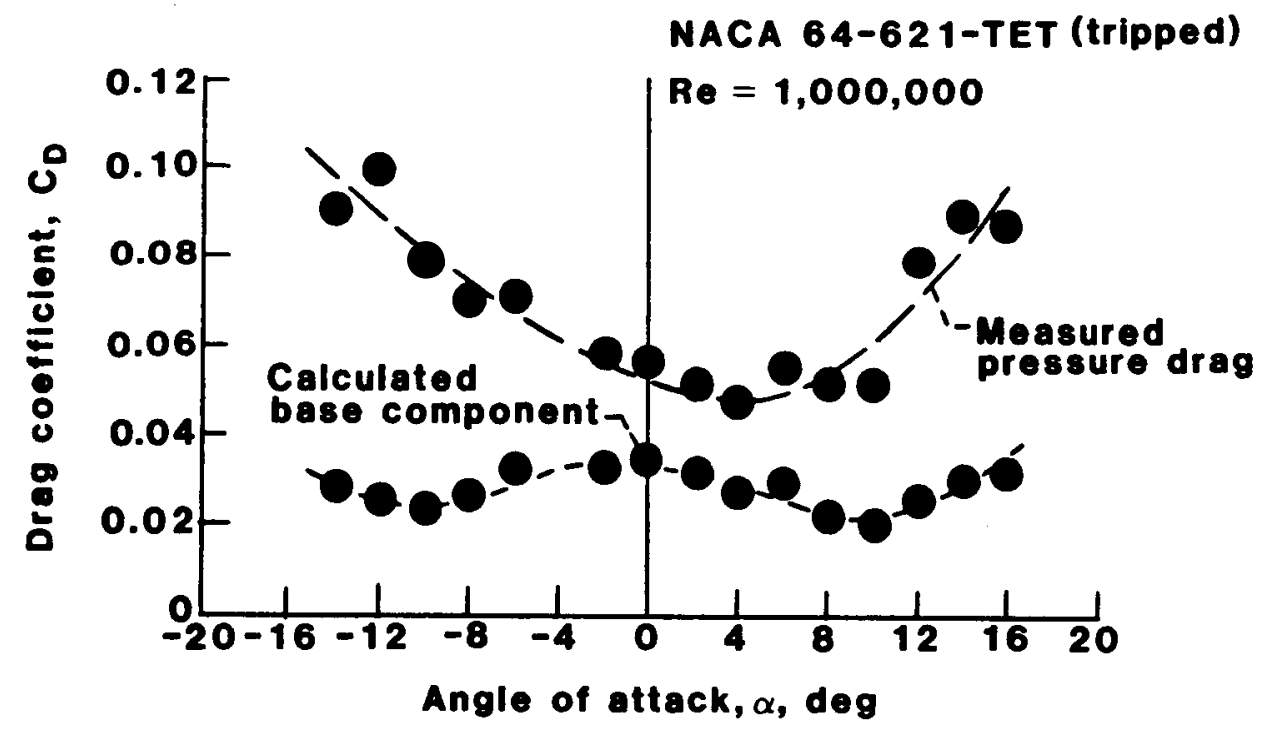

Figure 6.- Relative contribution of drag from the truncated base of the airfoil to the total measured pressure drag. 

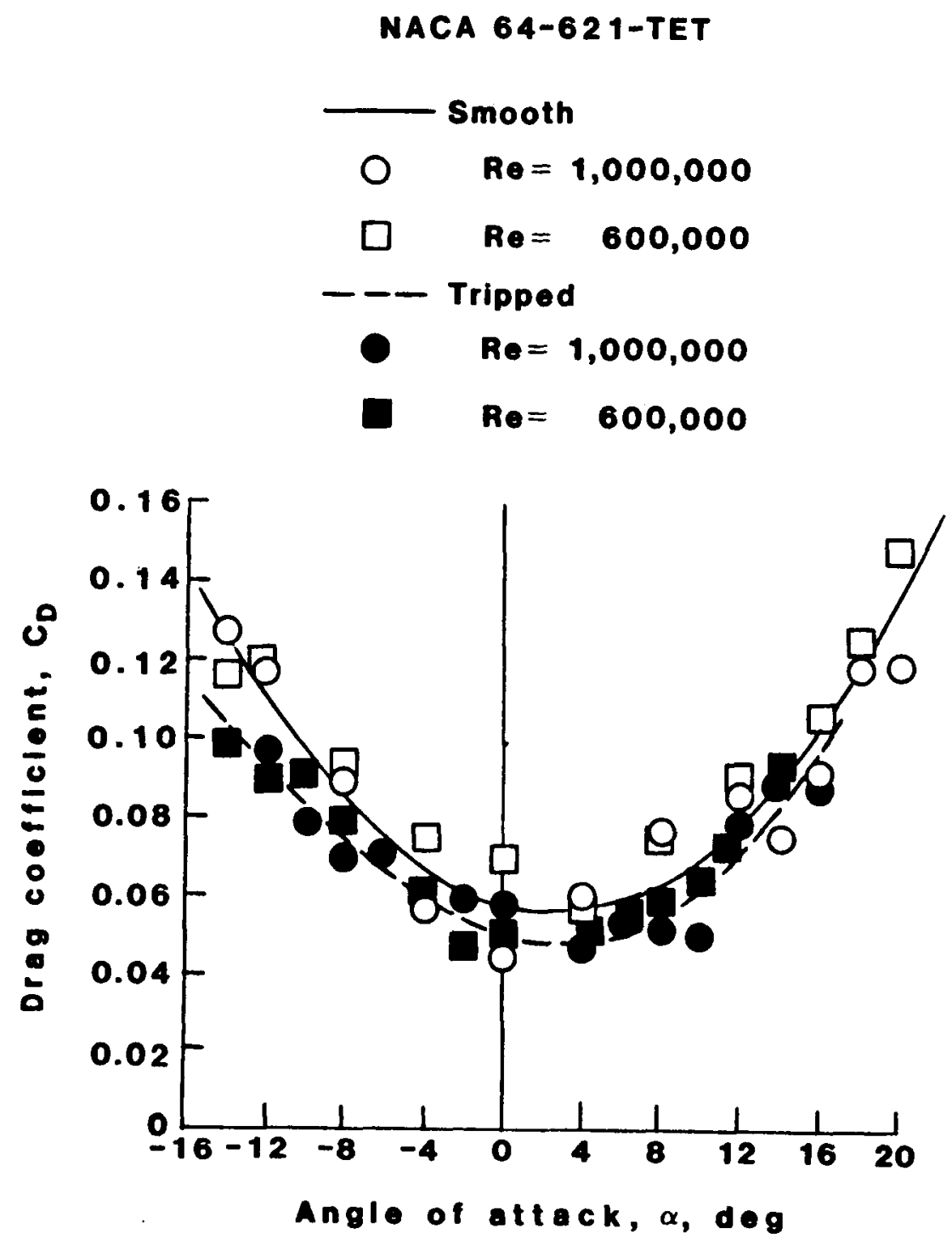

Figure 7.- Drag coefficients for the NACA 64-621-TET airfoils in the smooth and tripped conditions. 


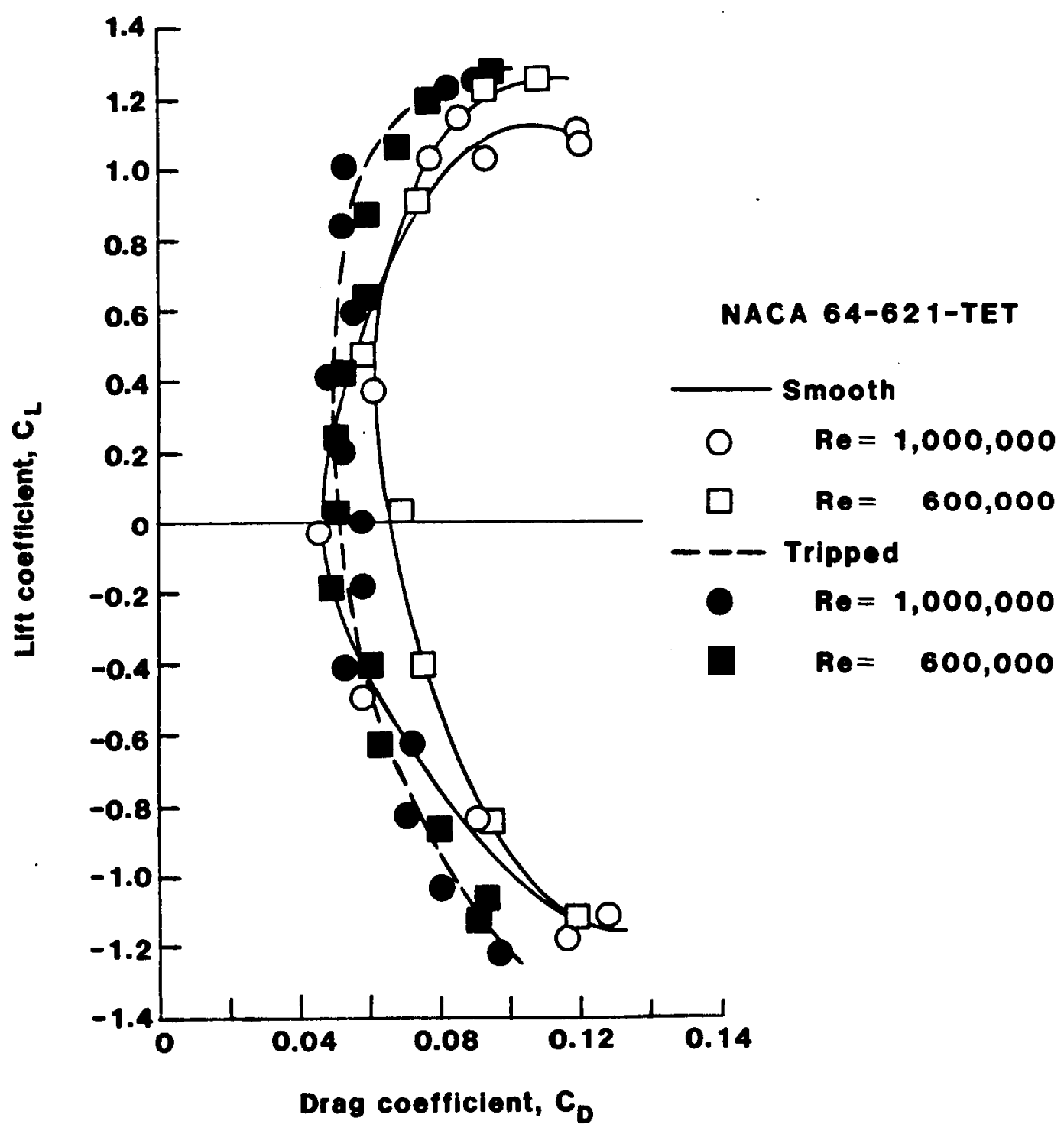

Figure 8.- Lift coefficients versus drag coefficients for the NACA 64-621-TET airfoils in the smooth and tripped conditions. 


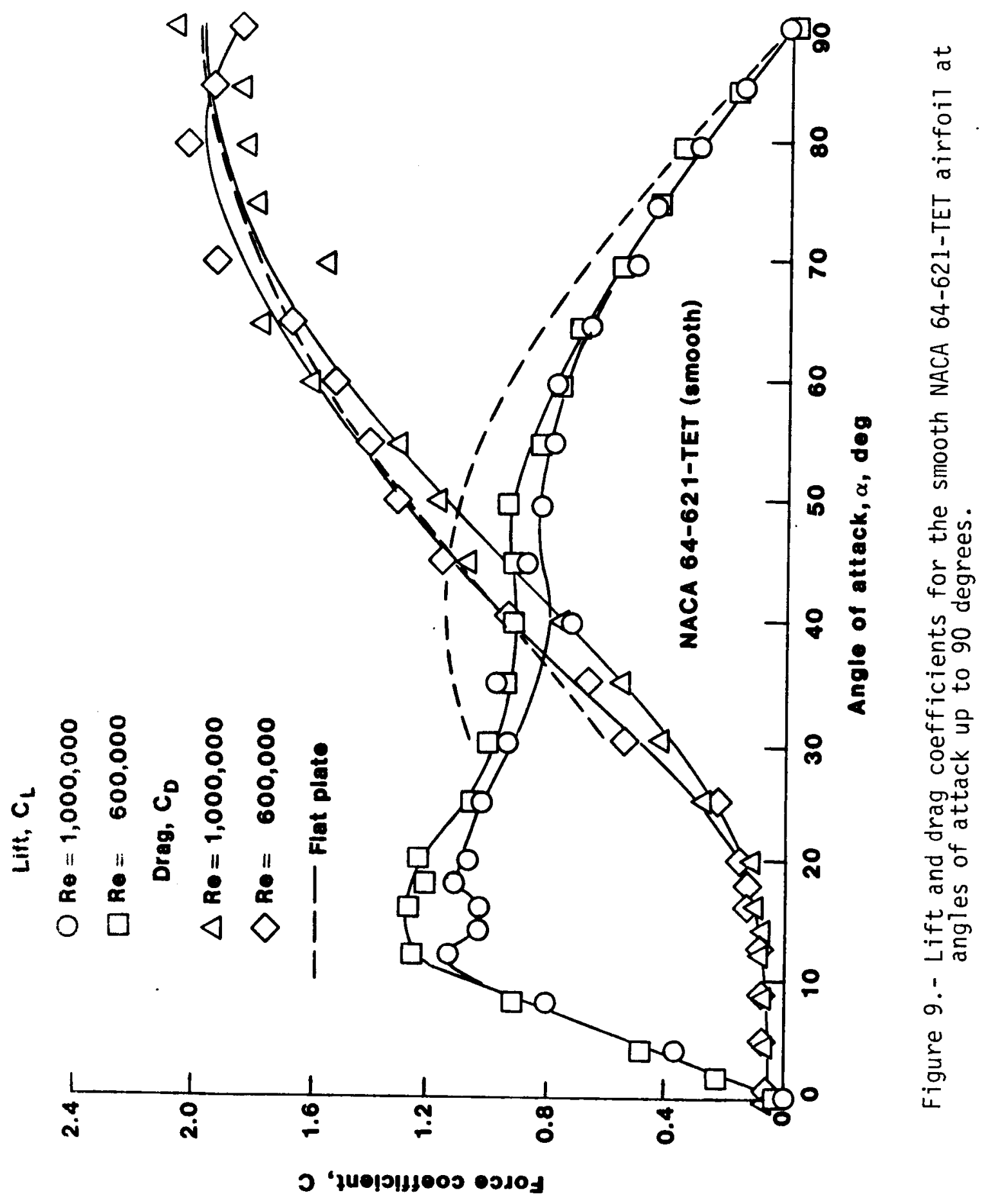




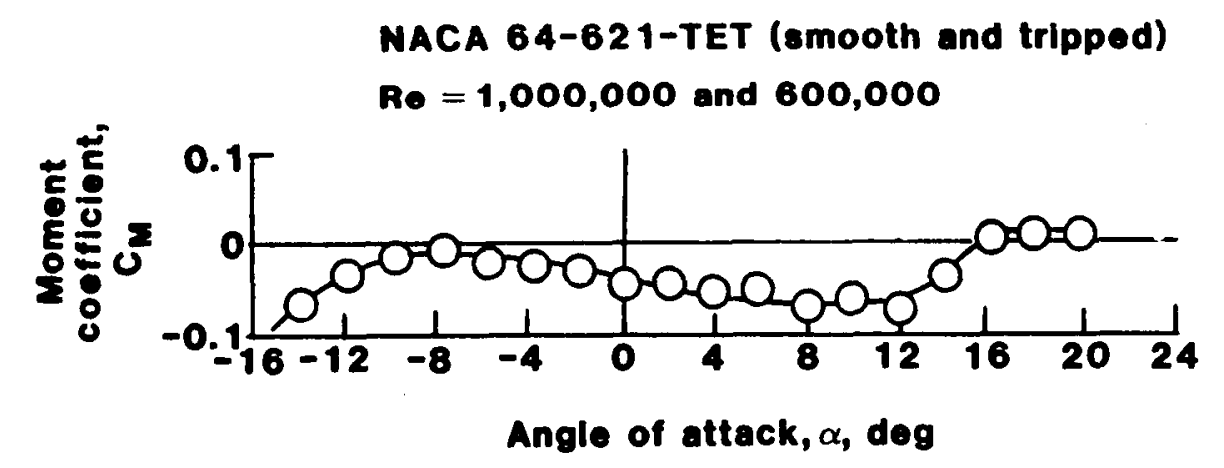

Figure 10.- Typical moment coefficients for the NACA 64-621-TET airfoils in the smooth and tripped conditions. 


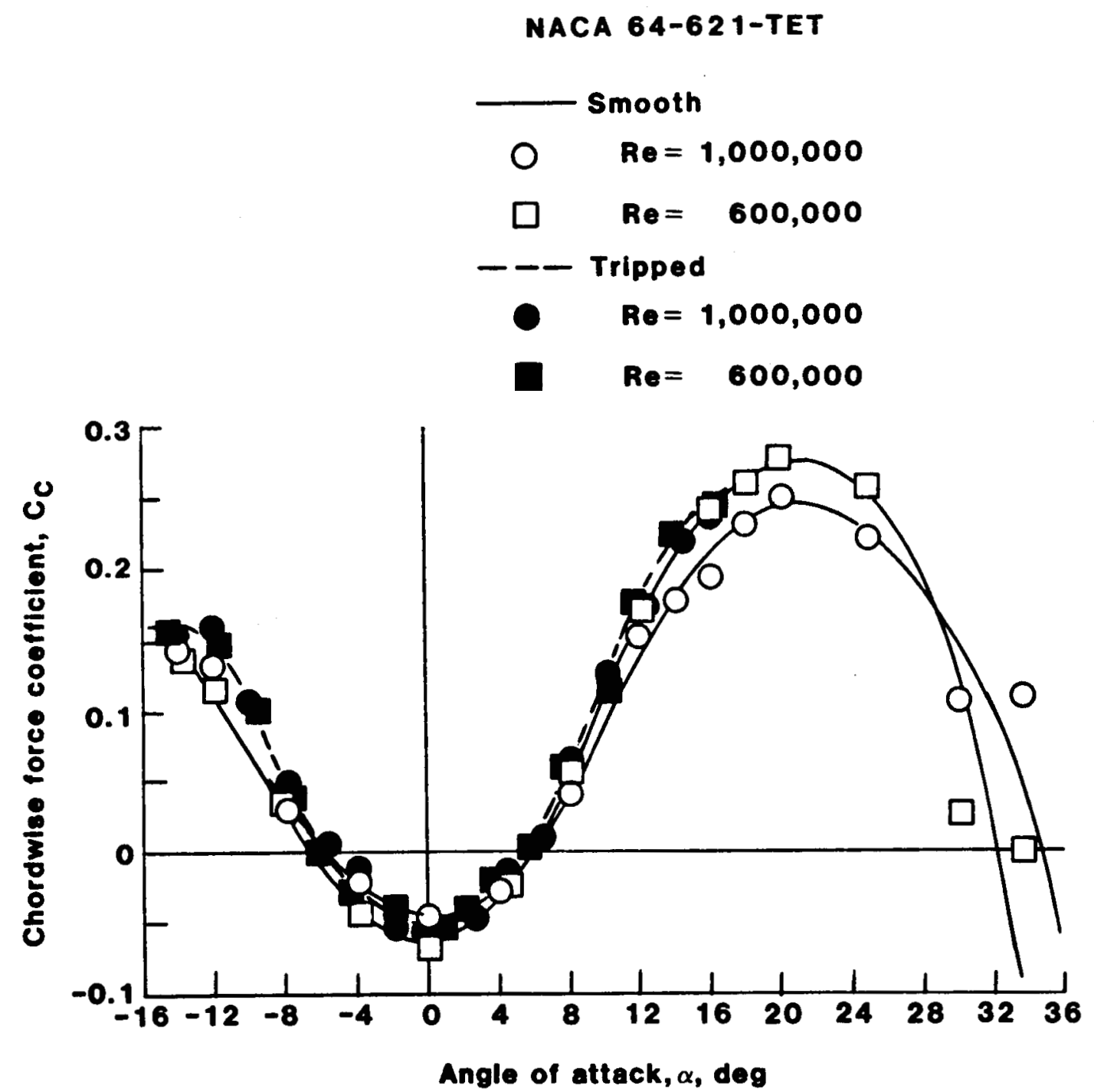

Figure 11.- Chordwise force coefficients for NACA 64-621-TET airfoils in the smooth and tripped conditions. 


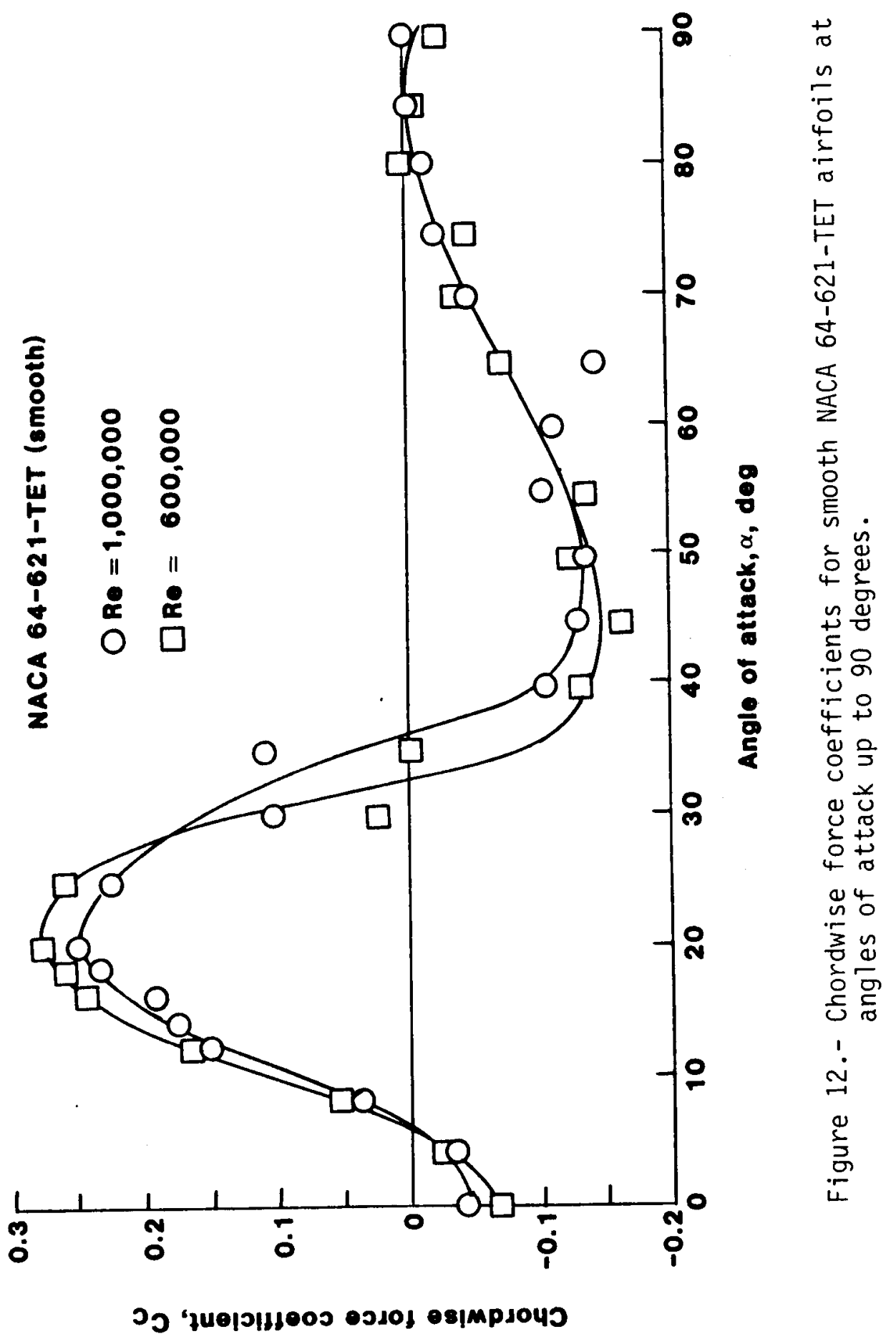




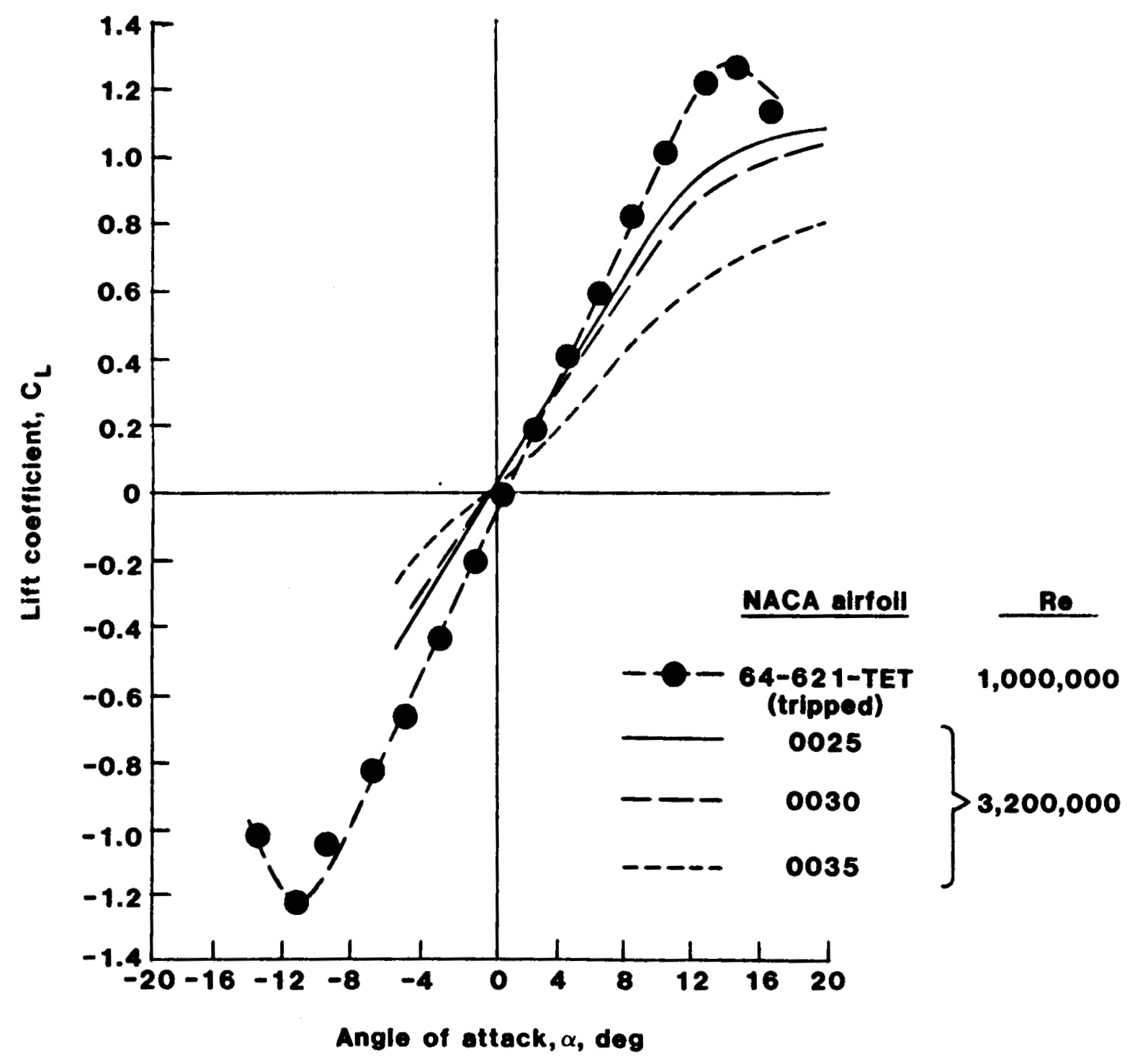

Figure 13. - Comparison of 1 ift coefficients, between the NACA 64-621-TET airfoil and thick airfoils in the NACA 4-Series (data for NACA 4-Series from Refs. 2 and 3 ). 


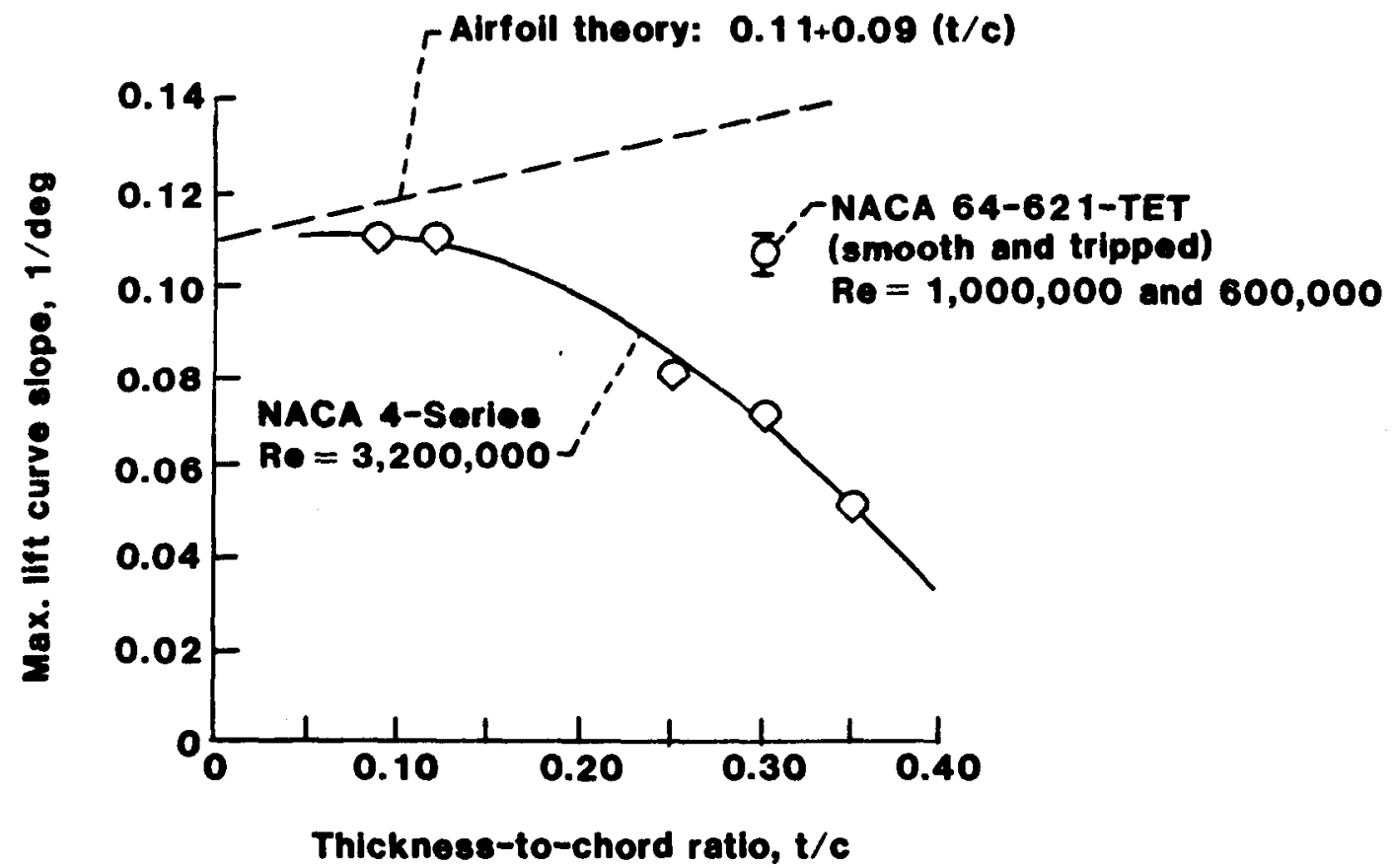

Figure 14.- Comparison of 1 ift curve slopes, for NACA 64-621-TET airfoils and NACA 4-Series airfoils (data for NACA 4-Series from Refs. 2 and 3 ). 

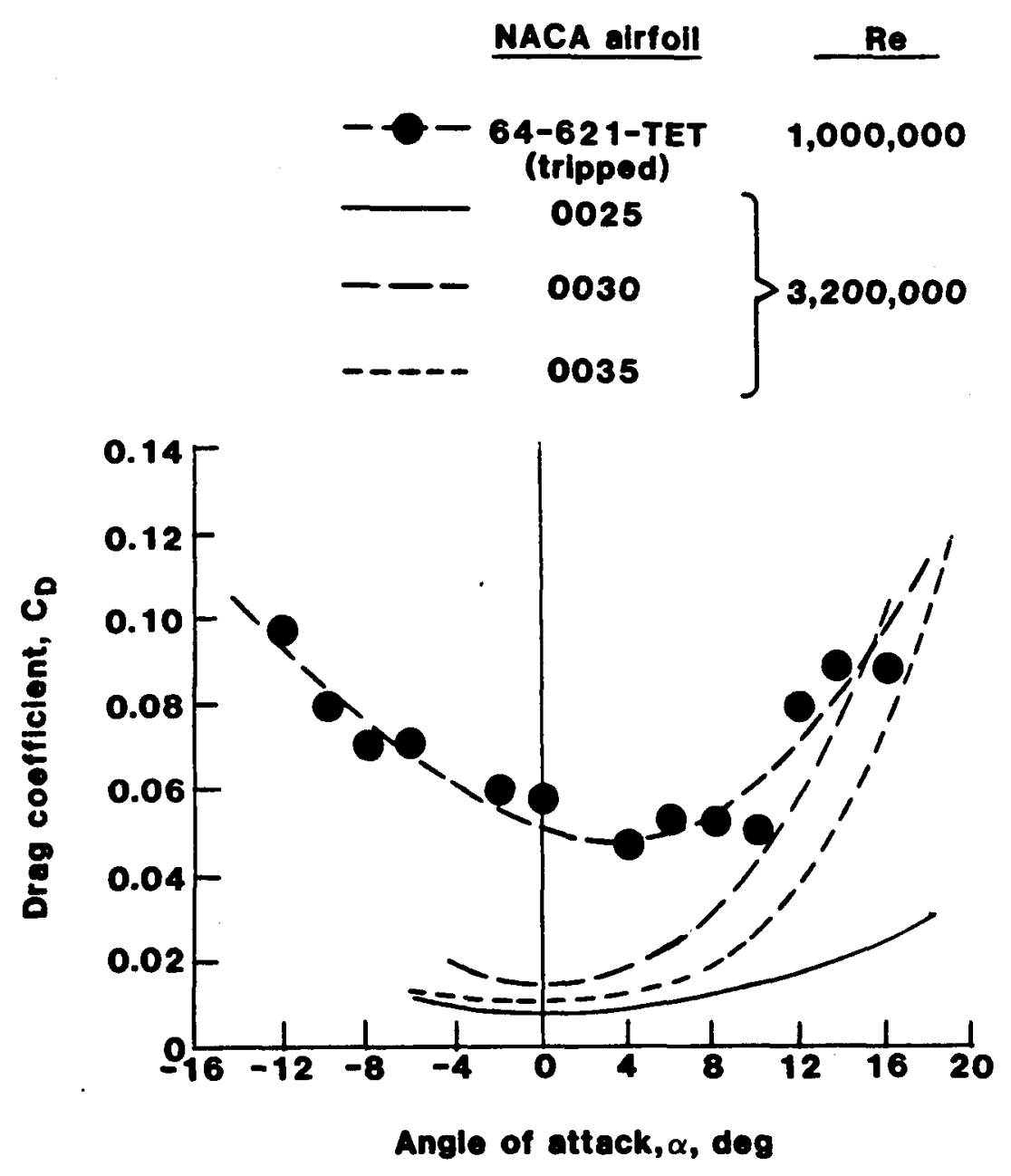

Figure 15. - Drag curve comparison, between tripped NACA 64-621-TET airfoil and thick NACA 4-Series airfoils (data for NACA 4-Series from Refs. 2 and 3 ). 


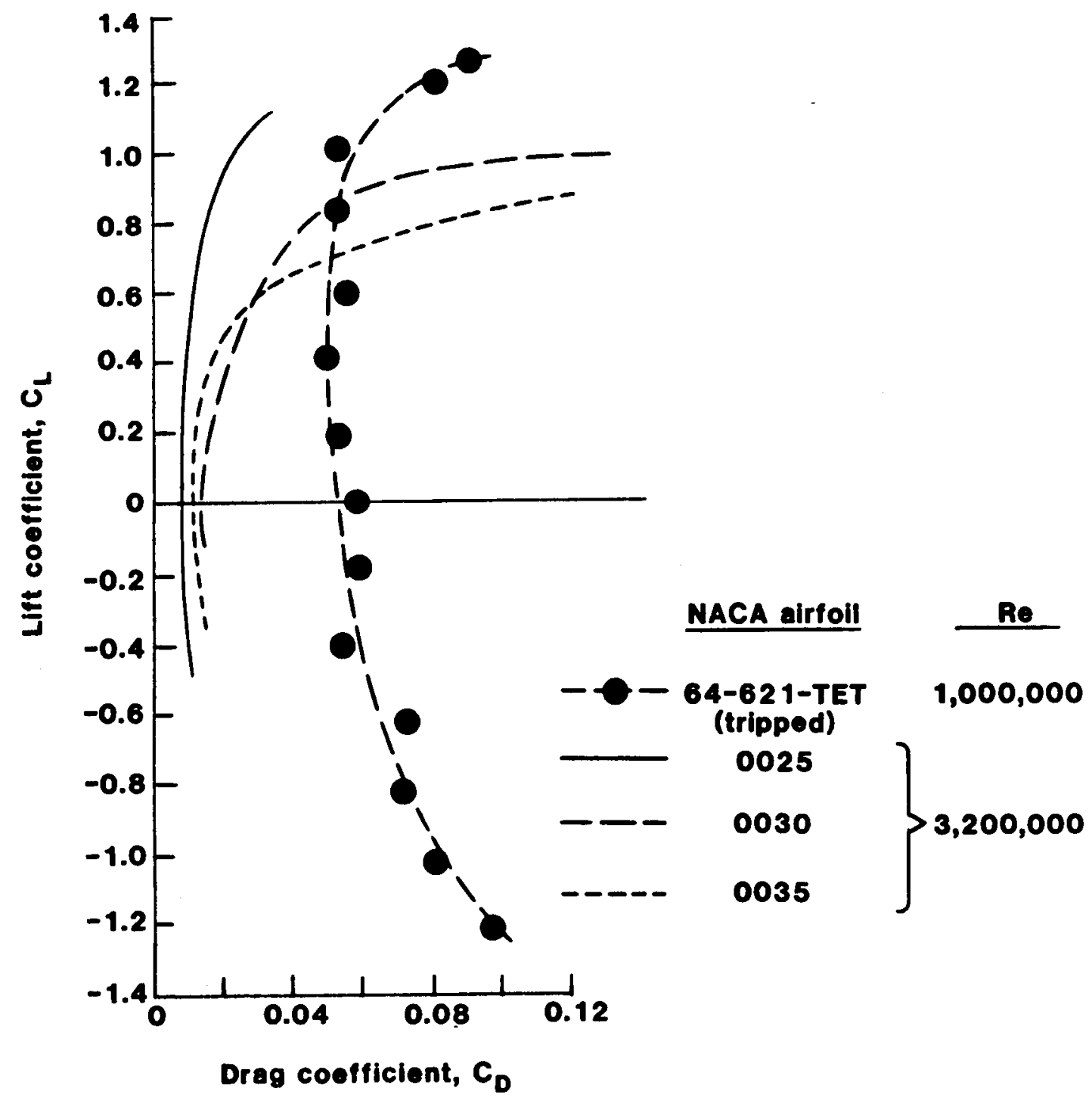

Figure 16.- Lift versus drag comparison, between tripped NACA 64-621-TET airfoil and thick NACA 4-Series airfoils (data for NACA 4-Series from Refs. 2 and 3 ). 
NACA airfoil

Re
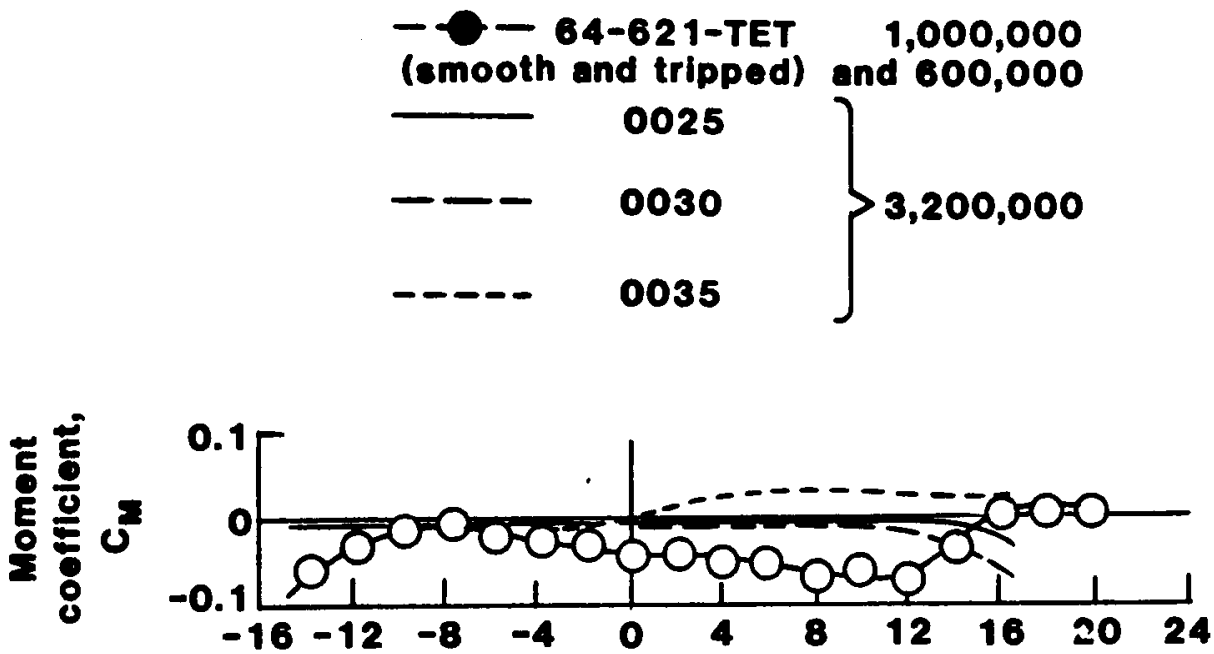

Angle of attack, $\alpha$, deg

Figure 17.- Moment coefficient comparison, between typical NACA 64-621-TET airfoils and thick NACA 4-Series airfoils (data for NACA 4-Series from Refs. 2 and 3 ). 

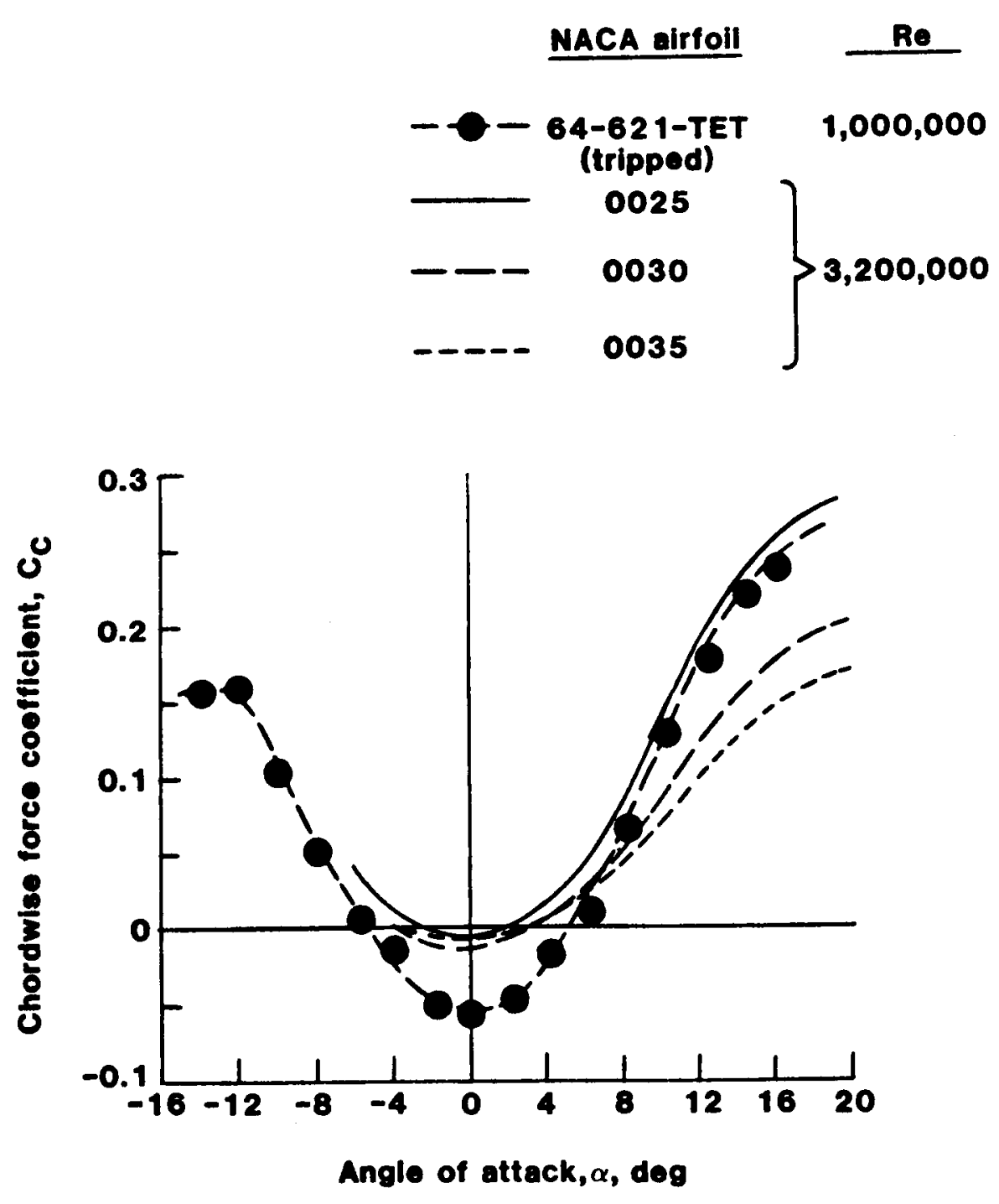

Figure 18.- Chordwise force coefficient comparison, between tripped NACA 64-621-TET airfoil and thick NACA 4-Series airfoils (data for NACA 4-Series from Refs. 2 and 3 ). 


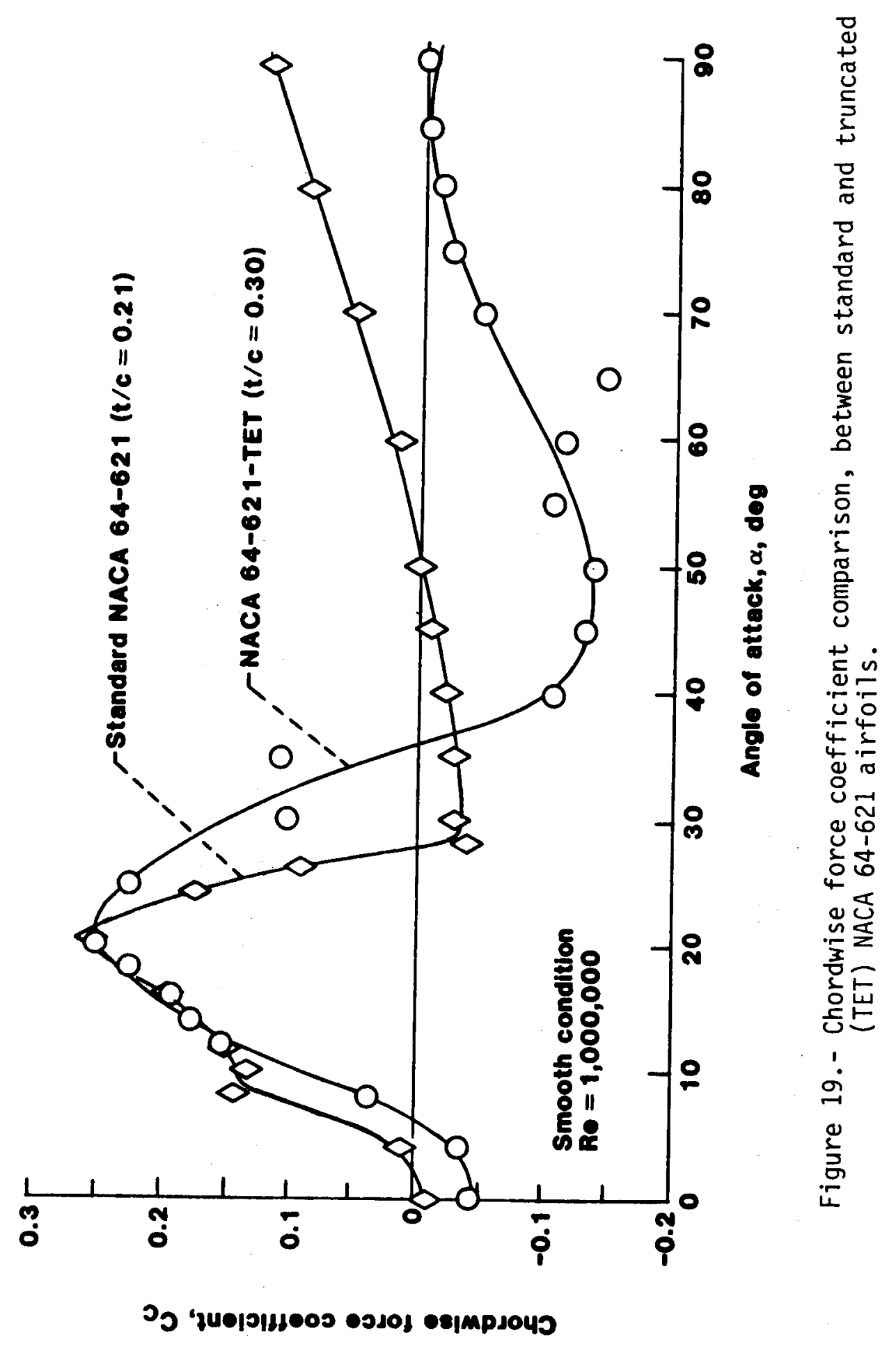




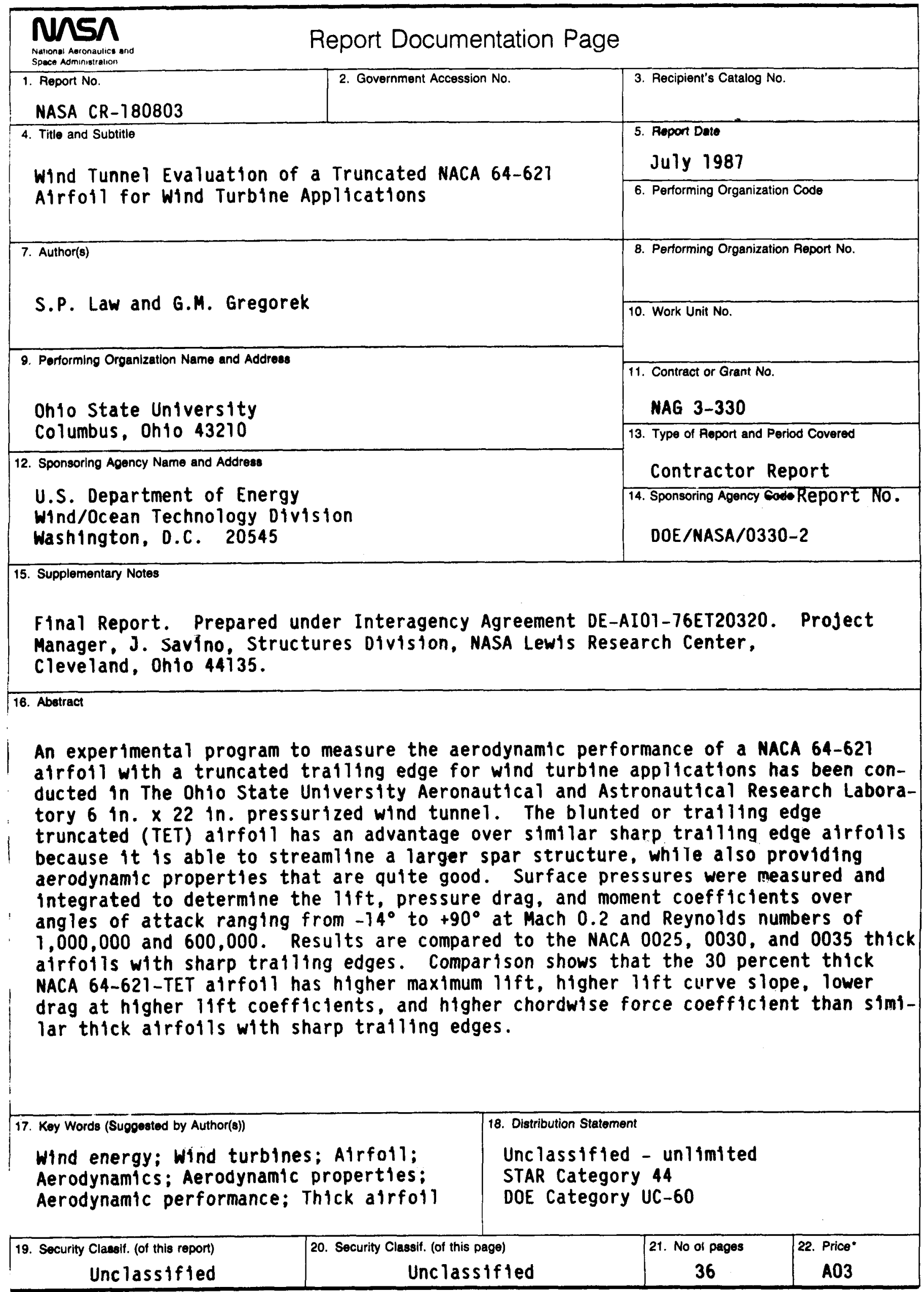

